\title{
Parents' Involvement in the Youth Justice System: Rhetoric and Reality
}

Peterson-Badali, Michele \& Broeking, Julia.

\author{
Version Post-print/accepted manuscript \\ Citation Peterson-Badali, M \& Broeking, J. (2010). Parents' involvement in the \\ youth justice system:Rhetoric and reality. Canadian Journal of \\ Criminology and Criminal Justice, 52, 1-27. \\ DOI http://dx.doi.org/10.3138/cjccj.52.1.1
}


Parents' Involvement in the Youth Justice System: Rhetoric and Reality ${ }^{1}$

In Press. Canadian Journal of Criminology and Criminal Justice.

DO NOT CITE WITHOUT AUTHORS’ PERMISSION

Michele Peterson-Badali

Julia Broeking

Department of Human Development and Applied Psychology,

Ontario Institute for Studies in Education, University of Toronto

Correspondence regarding this article should be addressed to the first author at the Department of Human Development and Applied Psychology, OISE, University of Toronto, 252 Bloor Street West, $9^{\text {th }}$ Floor, Toronto, Ontario, M5S 1V6, or via email to mpetersonbadali@oise.utoronto.ca

\footnotetext{
${ }^{1}$ The authors would like to acknowledge the justice officials who took the time to share their views for this study, and in particular to those who helped make the study possible by 'spreading the word'. Their unflagging commitment to the wellbeing of young people is inspiring. We would also like to thank Greg Brown, Vicki Mowat-Leger, and Jeff Wright for their support and assistance with research approvals and recruitment. This study was supported by Social Sciences and Humanities Research Council grant \# 410-2005-2054 to the first author.
} 


\begin{abstract}
The Youth Criminal Justice Act views parents as playing a critical role both preventing and addressing youths' criminal behaviour. However, the combination of lack of specifically defined goals for parental involvement and potentially conflicting messages regarding parents' roles may result in confusion for parents, youth, and those who work in the system, which may in turn reduce the efficacy of parents' involvement. Through in-depth semi-structured interviews with justice system officials $(n=41)$ who work with parents and young people, supplemented by direct courtroom observation of parents, we explored the reality behind the rhetoric of parental involvement. Results indicated that despite the fact that parental involvement can have an important impact on legal outcomes for young people, and while there may be some improvement in parental involvement post-arrest under the YCJA, parents are often not involved in ways that are seen as effective and meaningful. Two kinds of conflict are seen as contributing significantly to the gap between policy and practice: interpersonal conflict between youth and their parents, and conflict between the roles that parents are expected to play - simultaneously socializing youth and promoting their legal interests in an adversarial system. Recommendations for addressing the barriers to effective parental involvement are discussed.
\end{abstract}


The involvement of parents ${ }^{1}$ in the youth justice system raises complex issues and we have little information about how parental involvement 'works' in reality. Historically, Canadian youth justice legislation provided little explication of, and direction regarding, the roles of parents in their adolescent children's justice system experiences. The Young Offenders Act (YOA) stated that "parents have responsibility for the care and supervision of their children" (1984 s.3 [1] [h]). Consistent with this focus on responsibility and supervision, the Act allowed for parents to be compelled to attend court, and directed that parents receive certain information regarding their children (e.g., notices regarding arrest, summons, appearance, disposition, etc.; copies of medical, psychological and pre-disposition reports ordered by the court if parents attended court proceedings). Parents were also "asked to supervise various orders of the court, such as bail or probation conditions" (Varma 2007) and courts were directed to consider their ability to do so. In addition, parents were viewed as supports for youth under the YOA, which acknowledged that "because of their state of dependency and level of development and maturity, they also have special needs and require guidance and assistance" (1984, s. 3 [1] [c]). Implicitly placing parents in the role of advocates for young people's due process rights, the YOA mandated that police give detained youth the opportunity to consult with a parent prior to, and to have the parent present when, making a statement to police (1984, s. 56 [2] [c-d]).

These parental roles were carried forward from the YOA to the Youth Criminal Justice Act (YCJA 2002). The YCJA also expanded the focus on parents, placing responsibility for crime prevention, meeting the needs of young people, and guiding those at risk for criminal behaviour, in the hands of "communities, families, parents and others concerned with the development of young persons" (YCJA 2002, preamble). The YCJA directs that parents "be encouraged to support [youth] in addressing their offending behaviour" (YCJA 2002 s. 3 [1] [d] 
[iv]), and that parents and families be involved in creating meaningful opportunities for rehabilitation (e.g., in the context of extrajudicial measures and sentencing). Thus, in addition to advocacy, there appears to be a greater socialization role for parents under the YCJA (Bala 2003). However, like the YOA, the YCJA does not venture beyond making general statements about the role of parents. This combination of lack of specifically defined goals of parental involvement together with potentially conflicting implicit messages regarding parents' roles (e.g., legal advocacy vs. socialization) may result in confusion for parents, youth, and those who work in the system, which may in turn reduce the efficacy of parents' involvement.

Until recently there has been a dearth of information on whether and how parents are involved in the youth justice system and therefore no basis for evaluating its impact. However, several studies provide some direction in this regard. In terms of the frequency or extent of parental involvement, data from the US and UK indicate that many parents have no involvement when their adolescent children are arrested and brought into police custody (Grisso 1981; National Association for the Care and Resettlement of Offenders 1996, cited in Bala 2003). Similarly, in a Canadian youth self-report study, Peterson-Badali and Broeking (2004) reported that many youth did not contact their parents when they were arrested and only a small minority of parents came to the police station and/or were in the room with their children during police questioning. In contrast, parents are more involved at other points during youth justice proceedings (Davies and Davidson 2001; Peterson-Badali and Broeking 2004). Using court observation data, Varma (2007) found that $70 \%$ of bail hearings were attended by at least one parent and that sentencing proceedings were attended by parents in just over half the cases.

Even when parents are present with youth at the police station or court, youth reports and direct observations indicate that they are often passive and unengaged (Peterson-Badali and 
Broeking 2004; Varma 2007). As a result, Varma (2007: 253) raises the concern that "there is no meaningful channel for parents to participate in the court hearing or to be assisted in dealing with their children." This finding is echoed in a qualitative study of parental involvement from the perspective of 10 British Columbia parents (Hillian and Reitsma-Street 2003). Themes emerging from this study included system constraints that prevented effective involvement and intervention, and restricted parental participation. However, these studies were conducted under the YOA. Given the increased focus on parents in the text of the YCJA, the authors noted the potential for more effective parental involvement (Hillian and Reitsma-Street 2003; Varma 2007).

In light of past concerns regarding the lack of meaningful parental involvement, coupled with potentially conflicting messages in current Canadian youth justice policy and practice about what roles parents should play in their children's justice system experiences, it is vital to examine the perceptions and attitudes regarding parental involvement of those who work directly with youth and parents in the system. In the absence of a clear and specific rationale for parental involvement in the YCJA, justice system officials' interpretations of the purpose and goals of parental involvement, as well as their own views and experiences with youth and parents, likely shape their efforts to involve parents in youth justice proceedings and thus influence the extent to which the goals of parental involvement articulated in the legislation can be met.

To address these issues, we interviewed a number of 'key informants' - police, defence lawyers and crown attorneys, youth court judges and probation officers - who work in the youth justice system. In Part 1 of the current study, reported elsewhere (Peterson-Badali and Broeking, 2009), we compared respondents' interpretation of the legislative rationale for parental involvement with their own views regarding its importance in youths' justice system experiences 
and explored similarities and differences in the various groups' perspectives that might have implications for how they involve parents in youths' justice system experiences. Findings indicated that most youth justice respondents believed that the YCJA actively encourages parental involvement and many argued that it contains a stronger focus on parents than previous legislation. Reflecting the principles of the YCJA, officials indicated that legislators intend parents to play a role in enhancing the socialization of youth by preventing and addressing offending behaviour. They also acknowledged that one of the original goals of parental involvement was to offer youth support and advocacy given their developmental immaturity and many believed that this remains an important role for parents under the YCJA. Nevertheless, there were concerns that the Act encourages parental involvement in theory but that this does not translate into practice.

There were also interesting group differences in perspectives. Police were less supportive of parental involvement than other system players. They were also less likely than other groups to identify advocacy and socialization as legislative goals with respect to parental involvement and more likely to state that there is no rationale for parental involvement in the YCJA. Defence counsel, in contrast, unanimously stated that the YCJA encourages parents' involvement, and were most likely to state that its purpose was advocacy for youth (though not to provide legal advice). As a group, they also expressed concern that parents are expected to play conflicting roles, as supporting youth "in addressing their offending behaviour" (YCJA 2002, s.3[d][iv]) implies a socialization role that may be inconsistent with legal advocacy, especially in the context of an adversarial legal system.

Together with the previous literature, these data suggest the need to explore in more detail the 'reality' of parental involvement in youths' justice system experiences under the 
current legislation. Accordingly, to address both the hope expressed by researchers (Hillian and Reitsma-Street 2003; Varma 2007) that provisions in the YCJA would enhance meaningful involvement, as well as current concerns that legislative rhetoric has not translated into effective practice, we explored whether changes in how parental involvement is conceptualized under the YCJA are reflected in practice in Ontario. We examined this question from several angles.

Respondents were asked about the extent and nature of parents' involvement in their setting, the roles - both actual and ideal - that parents play in the system, and the impact of parents' involvement on processes and outcomes for youth. Where possible, similar variables were examined through direct observations of youth court proceedings. Finally, we asked youth justice respondents directly whether parents can fulfil the roles intended by legislation, what legislative changes (if any) are needed, and what recommendations they suggest for improving the effectiveness of parental involvement.

\section{Method}

\section{$\underline{\text { Participants }}$}

\section{Youth Justice Officials}

Five groups of key informants $(\mathrm{N}=41 ; 23$ females and 18 males $)$ who work in the youth justice system in southern and central Ontario - police $(n=10)$, defence lawyers $(n=8)$, crown attorneys $(n=7)$, judges $(n=7)$, and probation officers $(n=9)$ - were individually interviewed between June 2005 and September 2006. Police, judges and probation officers were drawn from three to five different areas (e.g., police divisions, courts, or districts) within Toronto. Defence and crown counsel came from four to five different locations throughout southern and central Ontario (including Toronto). The sample was diverse in age (with 27 of the 41 participants in the 30-49-year-old range) but homogenous in ethnic background, with 38 participants indicating that 
they were of white or European background. All participants had completed high school and $88 \%$ had completed a college, university or graduate degree. Respondents had significant experience in working with youth and parents. They had worked in their current occupation from one to 32.5 years $(\mathrm{M}=13.54, \mathrm{SD}=9.01)$. All respondents came in contact with at least some youth and parents each week.

\section{Courtroom Observations}

Four hundred and fifty courtroom observations of youth aged 12 to 19 (375 males, 73 females, 2 unknown) were conducted at two Toronto youth courts: 138 (31\%) at one court and $312(69 \%)$ at the second. Most defendants $(62 \%)$ were identified by courtroom observers as members of a visible minority group ${ }^{2}$. At the time of the study, defendants had been arrested and were in different phases of the court process. Fifty percent of defendants were represented by duty counsel and $48 \%$ were represented by private counsel. ${ }^{3}$ The majority of defendants were charged with offences against the person (e.g., assault) or with property offences (e.g., theft, mischief, possession of stolen property); see Table 1 for a list of all charges against observed youth as obtained through court dockets. Number of charges ranged from 1 to 68 (Median $=2$ ). Table 1 shows that the majority of observed proceedings were high volume (e.g., set dates). These proceedings happen very quickly and usually involve the defendant being called to stand up while the defence and crown counsel schedule the next court date.

Table 1 about here

\section{$\underline{\text { Procedure }}$}

Individuals who were experienced in working with young people in the youth justice context (e.g., police who work in youth bureaus, judges and lawyers who practice in youth courts) were recruited as part of a purposive sampling strategy. A detailed description of 
recruitment is provided in Peterson-Badali and Broeking, 2009. Following consent, individual interviews with police, lawyers, judges, and probation officers were conducted (mean length 1.3 hours). Data collection was discontinued once content analysis of interviews indicated that there was a saturation of themes (i.e., no new themes were identified from the interviews; Huberman and Miles 2002), resulting in the sample of 41 respondents.

\section{$\underline{\text { Measures }}$}

Youth Justice Officials Interview: A semi-structured parental involvement interview was developed for the five justice official groups. The interview included a combination of closedand open-ended questions and was comprised of three parts. Part 1, reported elsewhere, addressed respondents' understanding of the legislative rationale for parental involvement as well as their perceptions of parents' roles and responsibilities as intended by youth justice legislation (e.g., Do you believe that current youth justice legislation encourages parental involvement in young people's legal proceedings? Why/Why not?; What do you think is the current underlying rationale for parental involvement in youth justice proceedings? Why?; see Peterson-Badali and Broeking, 2009). Part 2 focused on respondents' personal experiences with parental involvement in their daily work, including the nature of parents' involvement (e.g., When parents are present during meetings/legal proceedings/at the police station, what is usually the nature of their involvement?), parents' actual and ideal roles in the legal process (e.g., What is your understanding of parents' role during legal proceedings? What should their role be?), and how parents' involvement (or lack thereof) impacts their decisions regarding youth or influences processes (e.g., In your daily work, does the presence or absence of a parent ever influence your thinking and/or decision making? Why/Why not?). Part 3 included questions regarding whether the system provides enough support for parents to fulfil their intended roles and whether parents 
can, ultimately, be involved in the manner intended by the YCJA (e.g., Do you think that parents are given enough support by the system to play an active role during legal proceedings? Why/Why not?; If the government were to give more resources (e.g., money) to the justice system to improve the role of parents during legal proceedings, what would you like to see those new resources be used for?). Each interview protocol included a set of questions that were identical for all participant groups as well as questions that were adapted or extended to relate to respondents' unique roles and experiences with respect to young people and parents. For example, all respondents were asked about young people's attempts to involve parents as well as whether and how parents involve themselves in the youth justice process overall, as well as in the particular context related to respondents' roles (i.e., police were asked about the police station, judges were asked about court appearances, and probation officers were asked about probation visits and/or conditions).

A content-based coding system was developed to capture informants' responses to openended interview questions. Although previous research with youth and parents (e.g., PetersonBadali and Broeking, 2004) suggested some themes that would arise from participants' responses (i.e., a priori categories), in most cases categories were developed inductively as participant interviews were coded, and thus reflected general themes derived from participants' specific open-ended responses. Categories were defined through labeling and provision of examples; most were non-mutually exclusive (i.e., different aspects of a response could be coded into more than one category). Twenty-five percent of the interviews were independently coded by second rater in order to establish the reliability of the coding system. Using Cohen's Kappa to correct for chance agreement, reliability ranged from .70-.1.0, with a mean of .91 . 
Many of the coding categories developed are self-explanatory from their title but those relating to the nature of parents' involvement (or parents' roles) are central to the analysis and merit explication. Participants' responses fell into one or more of several categories: 'No role', which included parents described as not present or, if present, who did not interact with youth or justice system personnel), 'General Support/Guidance’, which included social or emotional support and 'being there' for the youth, 'Socialization', ranging from parental supervision - e.g., of bail or sentencing conditions - and providing information to the system to acting as a positive role model for youth, holding youths responsible for their actions, or 'taking charge' of their children, and 'Legal Advantage', which comprised instrumental support and actions aimed at facilitating better outcomes for youths: obtaining legal counsel, advising youths to do what was strategically beneficial to their situation (such as remaining silent), picking youths up from the police station or acting as surety to facilitate release, getting youths to appearances or appointments, etc.

Courtroom Observation Protocol: In order to develop a protocol for recording observations related to parental involvement at court, the second author and three research assistants attended youth court proceedings to determine variables that could be reliably and unobtrusively observed. Through focused consultation with the research team, two different versions of the observation scheme were developed, one for bail hearings and one for all other proceedings. Both observation schemes focused on collecting information on defendants' physical appearance (e.g., sex, visible minority status), presence of parent ${ }^{4}$, visible involvement of parent in court proceeding, and interactions between defendants, parents, lawyers, and courtroom officials. Inter-observer agreement was established by having pairs of observers view proceedings together and independently complete observation protocols. Across 10 variables 
coded from the observations, mean agreement (using Cohen's Kappa to correct for chance agreement) was .89 , with agreement between pairs of observers ranging from .80 to .93 . Type of proceeding, defendant's age and charge information were obtained from court dockets made available through court order.

\section{$\underline{\text { Results and Discussion }}$}

\section{Extent and Nature of Parental Involvement}

\section{The Police Station}

Police officers were the primary respondents when the question of parental involvement at the police station was explored, although defence counsel, crowns and probation officers also commented on parents' role at the time of youths' arrest. With respect to their actual experiences, police reported a range of involvement that depends on the youth, the nature of the proceeding, and the parents. Consistent with youth reports (Peterson-Badali and Broeking 2004), a substantial minority $(n=4)$ indicated that parents are rarely involved at the police station and only one stated that in his experience the majority of parents are involved. Responses regarding parental roles were similar: most officers $(n=6)$ stated that parents' involvement at arrest is frequently limited to none, although half did state that parents can provide youth with support and general guidance (see Table 2), which is consistent with the legislation. Police elaborated that there is often little parents can do following arrest aside from picking up their child, unless the accused is interrogated. Most police reported that youth interrogations are now rarely conducted given the stringent criteria for admissibility of statements in court under the YCJA.

A number of officers raised concerns about the nature of parents' involvement at the police station. Police worried that parental anger at youth is not uncommon $(n=6)$ and that parents and youth frequently show visible disagreements at the station $(n=8)$. Officers saw the 
resulting parent-child conflict as interfering with police being able to do their job and as problematic for youth. One officer explained, "You can pretty much see who is mad and who's gonna get belted". It is interesting to note that defence lawyers were also apprehensive about parents' involvement at the police station, but for different reasons. One counsel argued, "At the police station, the nature of [parents'] involvement can be very negative for the kid if the kid gives a statement that is admissible because the parent was there. The parents often act as interrogators. ”

When asked what parents' role at the station should be, no officers suggested that parents should have no role. Police mentioned general support and guidance (including emotional support and protection) in numbers similar to the questions about actual involvement (see Table 2). In comparison to actual practice, more police noted that parents should assist youth legally and an even greater number argued that parents should play a socialization role (e.g., ensure that youth follow police conditions, take responsibility for their actions and do not engage in further criminal behaviour). ${ }^{5}$ Thus, while the parental roles that police articulated as ideal - advocacy, support, and socialization - are consistent with the legislation, with the exception of support, they were rarely mentioned as roles parents assume in reality.

Table 2 about here

\section{The Courtroom and Beyond}

Interview data. Consistent with previous research (e.g., Peterson-Badali and Broeking 2004), judges, lawyers, and probation officers identified a wider range of parental roles at court than police did at the police station, including support, socialization, and advocacy for youth (see Table 2). Many court officials argued that positively involved parents bring the youth and the system legal advantages (e.g., by providing information or by acting a surety). With the notable 
exception of defence lawyers, most informants also stressed that one of parents' roles during proceedings is to facilitate the socialization of defendants (e.g., enforcing probation conditions). In contrast to involvement at the police station, few respondents felt that parents played a limited role during court proceedings.

However, when asked about the nature of parents' involvement at court, like police, judges, lawyers, and probation officers did not view all aspects of parental involvement as positive. Many expressed concern that parents' involvement during lawyers' meetings (defence; $n=7$ ), court proceedings (crowns; $n=4$ and judges; $n=3$ ) and probation meetings (probation; $n$ $=6$ ) creates conflict and reported that parents and youth often show visible disagreements during meetings. Defence counsel in particular cautioned that inappropriate parental involvement during meetings can create conflicts around who constitutes the client. One lawyer explained, "I absolutely encourage parental involvement because the judges want it and it's better for outcomes of the case. It's kind of tough though because the kid is making the decisions and you don't want the parent to influence the kid". 6

When respondents were asked what role they felt parents should play post arrest, an even greater number argued that parents should offer their adolescent children general support and guidance (Table 2). Justice informants also maintained that parents should bring the youth (and the system) legal advantages and enhance the socialization and rehabilitation of youth. Probation officers in particular proposed that parents should "form a link between the youth and the system" and thereby make consequences more meaningful and effective.

Courtroom observations. For the purpose of data triangulation, parents' attendance and roles were observed at court. In 306 of the 450 courtroom observations (68\%) one or more parents was in attendance. As shown in Table 3, parental attendance varied with the type of 
proceeding, with bail hearings being the most frequently attended. ${ }^{7}$ Compared to Varma's (2007) observations of parents' court presence under the $Y O A$, a greater proportion of parents in the current study was present at bail hearings (70\% vs. 93\%, respectively), though the figures were similar for sentencing hearings (57\% vs. 64\%, respectively). In just under half the cases observed (49\%) court officials (typically defence lawyers but also judges) inquired whether the youth was accompanied by a parent. In cases where parents were absent, court officials rarely (15\%) inquired or explained why. Inquiries into parents' absence were observed most frequently during bail hearings due to questions by the judge or crown regarding the presence of a responsible person (i.e., exploring the question of surety). In the majority of these cases no reason for parents' absence was given.

Table 3 about here

In terms of the nature of parental involvement, courtroom observations revealed that the majority of parents were passive observers (see Table 4). Very few parents independently addressed the court and in the majority of these cases the parent made a practical comment (e.g., scheduling another court date). The proportions of parents who interacted with crown counsel or who addressed the judge were also very small. Interactions with the accused youth (e.g., laying a hand on his or her shoulder) or his or her lawyer were somewhat more common but still occurred in less than a quarter of the cases observed. Further testament to the passive nature of parents' role was that most accompanying parents remained seated in the audience section of the courtroom when the defendant's case was called.

Table 4 about here

It could be argued that high volume proceedings such as set dates do not allow for, or require, parents' involvement. However, parents appeared to observe trials, sentencing and plea 
hearings passively as well. ${ }^{8}$ Parents were somewhat more actively involved during bail hearings. Of those who attended, almost all (96\%) expressed their desire to assist the defendant in being granted bail and most (80\%) offered to act as surety (compared to 60\% in Varma's 2007 study). Almost all parents who acted as surety gave testimony (94\%) as to their ability to supervise the youth.

In summary, both the qualitative and quantitative data suggest that, with few exceptions, the extent and nature of parental involvement appears similar under the YCJA and the YOA, notwithstanding the greater emphasis and expanded roles articulated in the current legislation. The data revealed several types of concerns. First, at the police station parents were as likely to be seen as having no role to play as they were to support their sons or daughters, and parent-child conflict was frequently identified as interfering with effective involvement. Although officers stated that the practice of taking statements from youth has been significantly curtailed since the implementation of the YCJA, defence counsel were concerned that at times parents' involvement when they were at the station was to effectively serve as agents of the police by convincing their children to 'cooperate' or 'tell the truth'. This relates to interesting findings regarding the 'socialization' role of parents. The perceived discrepancy between actual and ideal parent roles was greatest at the police station, particularly with respect to socialization (i.e., intervening with youth to address and prevent offending behaviour). While police clearly valued this as a role for parents at the station, only one officer indicated that parents actually play this role. In contrast, defence counsel worried that undertaking this role could undermine youths' legal position.

The discrepancy between ideal and actual parental involvement was less dramatic in other contexts (e.g., at court or in the probation setting). However, courtroom observations suggest that parents' role at court remains passive (Varma 2007) in many instances, although the 
fact that parents appear to be more actively engaged in bail hearings is encouraging. It is interesting that, despite the fact that parents' presence is expected at court, officials explicitly inquired about this in only half of the courtroom observations, and when parents were not present the reasons were rarely sought. Finally, once again, the theme of conflict arose as an impediment to effective involvement.

\section{$\underline{\text { Parents' Influence on Youth Justice Processes and Outcomes }}$}

Lack of active and positive parental involvement does not necessarily pose a significant problem if parents have little impact on youth justice proceedings. ${ }^{9}$ It was thus important to explore youth justice officials' views about parents' influence on proceedings (either simply by being present or due to the nature of their involvement). In line with current youth justice policy, all but one respondent reported that parents can positively impact proceedings (see Table 5). Police indicated that youth who have involved parents are more likely to be released from the police station and from detention, a finding that is consistent with previous reports (PetersonBadali and Broeking, 2004, Carrington and Schulenberg 2003). Two officers noted that parents' presence at the station influences whether they press formal charges or consider pre-charge diversion for non-serious, first offences.

Table 5 about here

Similarly, the majority of judges, lawyers and probation officers $(n=27)$ stated that parents' involvement at court advantages youth directly in terms of better legal outcomes. One defence lawyer emphasized, "It makes a huge difference if [parents] show up at court. This often influences sentencing. The judges want them there. If they are there it shows there is structure, a home to support the kid". Judges elaborated that parents can sometimes influence the type or length of dispositions. Respondents also explained that parents bring legal advantages indirectly, 
by offering the youth instrumental and practical support (e.g., keeping track of appointments) or by providing important information about the young person that can inform sentencing and programming. Few respondents referred to legal advice when commenting on parents' influence on legal matters. Those who perceived parents as legal advocates usually emphasized that parents' task is to strengthen the youths' right to counsel. One crown counsel elaborated, "That they try to get legal counsel for the kid makes a huge difference and kids who don't have parents who do that usually don't get good legal counsel."

Six respondents noted that some parents can influence proceedings negatively. Judges, defence lawyers and one crown noted that, in cases where there is family conflict, parents' involvement can disadvantage the youth. In this context, conflict was at times described in terms of parents pressuring youth to make decisions that were contrary to the youth's wishes. One crown counsel worried, "I think they often force the young person to plead or they may force the young person to go to trial. Denial is an issue. The young person wants to plead guilty; the parent doesn't think they are guilty". In addition, respondents also emphasized that a parent who is a bad role model for the youth and/or who holds negative attitudes towards the system can negatively influence outcomes.

Findings from courtroom observations were consistent with respondents' views that parental presence has a positive impact, at least with respect to bail hearings. Of defendants whose parents attended bail hearings, $78 \%$ were granted bail, whereas only one out of six youth who had no parent present was granted bail, $\chi^{2}(1, N=80)=7.3, p<.01$. This finding stands in contrast to that of Varma (2007), who reported that parental presence alone was not associated with release on bail (though her observations indicated that if the court heard that a parent was able to supervise the youth, bail was more likely to be granted). It was also observed that parents 
influenced bail conditions at times (e.g., added specific house rules that they felt needed enforcement at home). ${ }^{10}$ However, sentence (custodial versus non-custodial) and decision to plead guilty were not significantly related to parents' presence during the proceeding. As Varma (2007) notes, the lack of a significant relationship between parental presence and disposition is not surprising in light of the impact of salient legal factors (e.g., the youth's prior record) at adjudication as well as the possibility that the sentence was agreed upon prior to the hearing.

Taken together, the interview and observation results suggest that parents can play a significant role in securing positive outcomes for youth, whether viewed from a legal advocacy standpoint (e.g., release from custody) or from a socialization perspective (e.g., influence on programming). This is a positive finding, but reinforces the importance of ensuring that parents are involved appropriately and effectively.

\section{Are Parents Able to Play the Roles Envisioned for them by the Legislation?}

Throughout this study it became apparent that respondents perceived specific barriers to effective parental involvement. When they were explicitly asked whether they thought parents are able to play a supportive role only $39 \%(\mathrm{n}=16)$ thought that most parents are able to play the roles envisioned for them by legislators; over $60 \%(n=25)$ stated that most parents are not able to play a supportive role, or that whether or not parents are able to be involved depends on the parent and the context. Informants (police and judges in particular) argued that many parents lack the economic and structural resources to be actively involved $(32 \%, \mathrm{n}=13)$. One police officer explained, "Most are single moms with three or four children; they can't afford to come”. Other informants noted that sociocultural factors (e.g., language 27\%, $\mathrm{n}=11$ ) prevent parents from playing a supportive role. Only a small minority of respondents $(12 \%, \mathrm{n}=5)$, all of 
whom were police or probation officers, believed that some parents either "don't' care" or "have given up" and are therefore unable to be involved.

When respondents were asked directly about system supports for parental involvement, most $(73 \%, \mathrm{n}=30)$ felt that parents are not given enough support to play the roles intended by the legislation. Officials $(49 \%, \mathrm{n}=20)$ worried that some parents do not understand what their role is and how proceedings work and argued that there is a need to provide parents with more legal information to enable them to participate in court proceedings. A third of respondents $(34 \%, \mathrm{n}=14)$ felt that there are not enough intervention services available to help parents support their child and criticized the lack of connectivity between systems (e.g., school and court), which makes accessing services difficult for parents. Finally, a smaller minority (17\%, $\mathrm{n}$ $=7$ ) of respondents argued that parents need more help with instrumental issues, such as transportation to and from court.

\section{$\underline{\text { Implications and Recommendations for Policy and Practice }}$}

\section{The Gap between Rhetoric and Reality}

In the following section we explore the policy and practice implications of respondents' perceptions and courtroom observations of parental involvement and examine recommendations for promoting more effective parental involvement in light of current findings and previous research.

Youth justice officials view the YCJA as placing a greater emphasis on parental involvement than its predecessor (Peterson-Badali and Broeking, 2009). In the current study, the value of parental involvement was reflected in both interview and courtroom observation data indicating that certain critical legal outcomes (e.g., release on bail) were related to parents' presence and role. Nevertheless, officials expressed concern that policy is not translating into 
practice, at least in Ontario. Examination of the interview data indicates that the extent of this gap differed according to the specific parental role(s) that respondents identified as important. Advocacy and general support for youth (seen as significant parental roles under both the YOA and the YCJA) were viewed fairly similarly when ideal roles were compared with perceptions of actual practice. The larger gaps appeared with respect to parents' role as socialization agents newly carved out under the YCJA - and this varied by respondent group. Police and probation officers in particular felt that parents ought to be assuming this role but that it was not being adopted in practice. In fact, though police talked about support for youth as a general role that parents take on in their interactions within the youth justice system, their experience of parents at the police station was that they often had no role to play. This is consistent with their perception (unique among the youth justice groups) that the YCJA does not encourage parental involvement (Peterson-Badali and Broeking, 2009).

The gap between policy and practice was also reflected in the courtroom observation data. For example, parental presence in court was more common in the present study than in Varma's (2007) study with respect to bail, but not sentencing, hearings. In addition, the passive nature of parents' presence at court reported by Varma (2007) was observed in the present study as well. The 'good news' that a majority of parents were present in most types of hearings was tempered by the fact that (with the notable exception of bail hearings) they rarely interacted with the youth, his/her lawyer, the crown, or the judge. On the 'system' side, while court officials (e.g., defence counsel, judge) asked or commented about parents' presence in approximately half of the proceedings observed, when parents were not present, their absence was not addressed or pursued in any way. In sum, while there may be some movement in the direction of greater parental involvement post-arrest under the YCJA, there is agreement both across respondent 
groups and between the interview and observational data that there is still significant room for improvement.

The Need to Resolve 'Conflict'

Two kinds of conflicts recurred throughout the interviews with youth justice officials as preventing policy from translating into effective practice. The first is conflict between parents and youth, explicitly described by all informant groups as interfering with their ability to promote successful outcomes for youth and/or 'the system'. The second is conflict between the roles that parents are expected to play: simultaneously socializing youth and promoting their legal interests in the context of an adversarial system. Defence lawyers, in particular, explicitly reflected on this problem. For example, they criticized that police sometimes try to utilize parents to gather statements, which they felt should not be the role of parents. One defence lawyer stated, "There is a real conflict in the sense that when someone is being investigated by the police, in a sense you want to minimize the information and hinder the investigation. But what society expects of parents is different. They are supposed to teach their kids right from wrong. So that creates problems."

This conflict between parental advocacy and socialization roles mirrors - and may emanate from - broader beliefs about parental responsibility for youth offending. In examining parental involvement under the YOA, both Hillian and Reitsma-Street (2003) and Varma (2007) noted that prevailing societal beliefs, which are reflected -- tacitly and explicitly -- in youth justice and parental responsibility legislation, blame parents for youths' antisocial behaviour. In the present study, this perspective was voiced by a minority of respondents overall, but more frequently by police and probation officers, who talked about the difficulties with parents who have a negative attitude toward the legal system, or who have 'given up' on their children and 
advocated punishing parents who 'refuse' to get involved. At the same time, the YCJA calls on parents to support their children, both in terms of advocacy and assistance in addressing their offending behaviour. Thus, parents may be seen as both the cause of and the solution to youth offending (Varma 2007) and expected both to support youth in the context of an adversarial legal process as well as to support the efforts of the system to hold youth accountable and prevent future crime. For parents, this perspective results in experiences of shame, stigma, and isolation, which likely lead to avoidance rather than promote greater involvement with the youth justice system (Hillian and Reitsma-Street 2003).

In previous research, as well as in the present study, practical barriers to active parental involvement have been suggested both on the system side (Davies and Davidson 2001; Varma 2007) as well as in relation to parents' abilities or limitations (e.g., employment and childcare constraints; Davies and Davidson 2001) or the nature of the parent-child relationship (Feld 2000). While youth justice officials recommended solutions to some of these barriers (and some talked about what they already do in their practice to minimize them), addressing the more fundamental role conflict is necessary if parents' involvement is to be meaningful and effective. Some strategies for addressing these issues are discussed in the following section. Improving the Effectiveness of Parental Involvement

Despite the fairly widespread concerns regarding the effectiveness with which parents are involved under the YCJA, the majority of respondents $(63 \%)$ felt that there was no need to change the legislation. Officials (44\%) argued that the legislation could be effective if implemented as intended or that it is necessary to educate people working in the system about the legislation. A small number of officials (17\%) felt that the problems underlying the issue of parental involvement are social in nature and cannot be addressed through legislative change. 
Those (30\%) who advocated changes to the legislation (half of whom were police officers) did so on the basis of the need to hold parents more accountable for their children, which is consistent with the parental blame perspective discussed above.

Youth justice officials' suggestions for improving the effectiveness of parental involvement fell into several broad categories. The majority felt that resources should be put into legal support and public education programs (59\%). Officials elaborated that for parental involvement to be more effective, parents need to be provided with legal information at the police station and at court. Within this context, respondents noted that there is a need for liaison workers at court and more assistance with bail and legal aid. In addition, data from this study suggest that parents and youth need to be educated about the importance of parents' involvement (i.e., that parents can be influential in what happens to youth) as well as what parents can (and are expected to) do at the police station, at court, and in the context of extrajudicial measures or dispositions. In addition to education for parents, justice officials expressed concern that some professionals working within the system (especially those who do not specialize in youth justice) do not understand the complex nature of parental involvement. They highlighted the need to educate system players about factors that affect parental involvement in legal proceedings. The differences in respondent groups' perceptions of parents' roles and the problem of role conflict discussed above reinforces this call for education of those working in the system in order to encourage a shared and consistent view regarding parents' roles (e.g., between police and defence counsel, for example).

In addition to the need for general education, the creation of a 'youth justice support worker' role could address both types of conflict described above, and provide needed information and support to youth and parents. Current findings suggest that there may be a need 
for youth to be supported by someone other than a parent at the police station. This would ameliorate the problem of parent-child conflict as well as the expectation that parents somehow can and should both advocate for youth and engage in their (moral) socialization. Appropriately trained workers could help diffuse parent distress and anger to enable parents to play a supportive role and be involved in ways that advantage youth (e.g., acting in the role of a responsible party to whom police can release youth, supporting the use of extrajudicial measures where appropriate). At court, workers could assist with many of the issues that youth court officials raised as barriers to effective parental involvement, including parent education regarding processes and resources and facilitating access to appropriate services within (e.g., interpreters) and outside (e.g., mental health or social services) the court system.

Creating an independent support worker role might also help address another role concern raised by some respondents in the current study (particularly lawyers): the notion that parents should provide legal information and/or advocacy for youth. This role was never explicitly articulated in legislation. However, from the time of the YOA the notion that parents should provide guidance and assistance to youth as a result of their lack of full maturity, together with the provision of the right to consult with a parent prior to police questioning, were interpreted to mean that parents were to safeguard their children's due process rights and provide “meaningful and useful advice" (Stuart 1985: 19; Tustin 1994). Although not addressed at length by respondents in the present study, both defence counsel and crown attorneys stated clearly that parents' legal advocacy should take the form of ensuring that their children get access to appropriate legal counsel and that parents do not have the expertise to provide legal information or advice, or otherwise substitute for a lawyer. This concern is supported by research indicating that many parents show deficits in their understanding of the role of lawyers, lawyer-client 
privilege, and police interrogations (Harvell and Woolard 2005) and that many parents do not know how to assist their children during police or court proceedings (Dixon, Bottomley, Coleman, Gill, and Wall 1990). While support workers would not provide legal advice to youth, they could ensure that youth get access to proper legal advice. In this study lawyers indicated that this is one of the most important things parents could do for their children and that it made a significant difference to outcomes for youth. Clarifying that parents should not be expected to provide legal advice to youth (while ensuring that youth receive such advice) also addresses the conflict between the parental roles of advocacy and socialization and allows parents to be parents: to provide emotional support and moral guidance to youth.

Interestingly, justice officials believed that one way to ensure parents' involvement in all aspects of their children's lives (including in legal contexts) is to invest in early prevention and intervention programs. Thus, officials located the issue of parental involvement within the larger contexts of parenting and child development. This recommendation also reflects officials' perceptions that focusing on parental involvement in legal contexts alone may not solve the problems society is facing with respect to youth crime. Officials emphasized that positive parental involvement in legal contexts is important when addressing the problems of youth who have already offended but that youths' offending behaviour is often a reflection of underlying emotional or systemic problems that should be addressed earlier in children's lives.

Consequently, most officials indicated that youth crime needs to be addressed by targeting areas such as early childhood education and positive parenting. Most justice system informants also argued that there is a lack of mental health and counselling programs that may help parents address their children's needs. Thus, officials strongly believed that for parental involvement in 
legal proceedings to be effective, parents need to be supported and empowered before as well as after their adolescent child commits a crime.

\section{$\underline{\text { Limitations and Future Directions }}$}

Notwithstanding the aforementioned implications certain study limitations should be considered when interpreting findings. First, the sample was purposively selected and therefore presents the views of a small number of professionals working within the youth justice system in Ontario. Respondents' views may not generalize to those in other provinces and territories. Future studies should include personnel in other Canadian provinces and territories to add valuable insight to the issues examined here, particularly in terms of the question of how differences in implementation of the Act are reflected in officials' perceptions of, and reported practices with respect to, parental involvement. With respect to the small sample size, recall that data collection continued within each respondent group until there was sufficient consistency in responses that saturation of themes was reached. Thus, we can state with some confidence that the views expressed do represent with a reasonable degree of accuracy and comprehensiveness those of youth justice officials in Ontario.

Courtroom observations supplemented interviews with youth justice officials, as the triangulation made possible by multiple data sources and methods facilitates substantiation of constructs and hypotheses (Huberman and Miles 2002). The courtroom was selected as a practical setting because of the public nature of court hearings. One of the advantages of naturalistic observations is that they allow for the collection of data that reflect the constraints of the natural environment of the observed subject (Huberman and Miles 2002). However, there are also certain limitations associated with observational research. First, it was impossible to collect identifying information for observed cases and therefore we could not follow defendants 
throughout their court experience. Thus, each case was treated as an independent observation though it is possible that the same youth and/or parents were observed at different times. In addition, naturalistic observation allows for limited control over variables and confounds. Finally, for some proceedings court officials requested that anyone not involved as a witness be removed from the court. Thus, some information on parents' involvement might have been missed.

Notwithstanding these limitations, taken together, the perspectives of youth justice officials and courtroom observations provide valuable insight into the reality of parental involvement in Ontario's youth court system. Exploring the extent to which youth and parents view parental involvement similarly to justice system officials is vital to efforts to facilitate effective and meaningful parental involvement. To this end, we have examined young people's perceptions and experiences with respect to the extent and nature of their parents' involvement (Broeking, 2008; Broeking and Peterson-Badali, 2009a) as well as the predictors and outcomes of that involvement (Broeking, 2008; Broeking and Peterson-Badali, 2009b; Clarke and PetersonBadali, 2009). Incorporating evaluation research into the design of strategies developed to enhance positive and effective parental involvement, or to protect youth where parents' involvement is not is not feasible or advisable, is also critical to assess whether the goals of such measures are being achieved. 


\section{References}

Bala, Nicholas

2003 Youth criminal justice law. Toronto: Irwin Law.

Broeking, Julia

2008 Parental involvement in youth justice proceedings. Unpublished Doctoral

Dissertation, University of Toronto.

Broeking, Julia and Michele Peterson-Badali

2009a The extent and nature of parental involvement in youth justice proceedings. Under review.

Broeking, Julia and Michele Peterson-Badali

$2009 \mathrm{~b}$ Predictors and outcomes of parental involvement in youth justice proceedings. Manuscript in preparation.

Carrington, Peter and Jennifer Schulenberg.

2003 Police discretion with young offenders. Ottawa: Department of Justice Canada.

Clarke, Maggie and Michele Peterson-Badali

2009 The parent-child relationship and parents' involvement in youth justice proceedings. Manuscript in preparation.

Davies, $\mathrm{H}$ and $\mathrm{H}$ Davidson

2001 Parental involvement practices of juvenile courts. Report to the Office of Juvenile Justice and Delinquency Prevention. Washington, DC: United States Department of Justice. 
Dixon, David, Keith Bottomley, Clive Coleman, Martin Gill and David Wall

1990 Safeguarding the rights of suspects in police custody. Policing and Society 1: 115140.

Feld, Barry

2000 Juveniles' waiver of legal rights: confessions, Miranda, and right to counsel. In

Thomas Grisso \& Robert Schwartz (Eds.), Youth on trial. A developmental perspective on juvenile justice (pp.105-139). Chicago: University of Chicago Press.

Grisso, Thomas

1981 Juveniles' waiver of rights. Legal and psychological competence. New York: Plenum Press.

Harvell, Samantha and Jennifer Woolard

2005 Parental involvement in delinquency proceedings: An assessment of parents' knowledge and attitudes. Paper presented at the Biennial Meeting of the Society for Research in Child Development. Atlanta, GA.

Hillian, Doug and Marge Reitsma-Street

2003. Parents and Youth Justice. Canadian Journal of Criminology and Criminal Justice 45: 19-43.

Huberman A. Michael and Matthew Miles

2002 The qualitative researcher's companion. Thousand Oaks, CA: Sage.

Peterson-Badali, Michele and Julia Broeking

2009 Parents' involvement in the youth justice system: The view from the trenches. Canadian Journal of Criminology and Criminal Justice 51: 255-270. 
Peterson-Badali, Michele and Julia Broeking

2004 Parental Involvement in Youth Justice Proceedings: Perceptions of Youth and Parents. Ottawa: Department of Justice.

Stuart, B.

1985 The Young Offenders Act. Provincial Judges Journal 9: 13-33.

Tustin, Lee

1994 Caught in the act: A user's guide to the youth justice system and Young Offenders Act. Don Mills, ON: Addison-Wesley.

Varma, Kimberly N.

2007 Parental involvement in youth court. Canadian Journal of Criminology and Criminal Justice 49: 231-266.

\section{Legislation}

Young Offenders Act, R.S.C. 1984, c. Y-1.

Youth Criminal Justice Act, S.C. 2002, c.1. 
Table 1. Charges and Proceeding Type for Cases Observed at Court

(a) Charges

\begin{tabular}{cc}
\hline Number of charges & $\begin{array}{c}\% \text { of total } \\
\text { charges }\end{array}$
\end{tabular}

Violent offence

199

26.1

44.2

Property offence

159

20.8

35.3

Drug

79

10.4

17.6

Other Criminal Code

181

23.7

40.2

Traffic Code

9

1.2

2.0

Administrative

135

17.7

30.0

Missing

1

0.1

0.2

Total

763

100.0

*Note: Percentages in this column are based on 450 separately observed proceedings, and add to more than $100 \%$, because many proceedings involved more than one type of charge.

(b) Type of Proceeding

\begin{tabular}{rr}
\hline Number of proceedings & $\%$ of proceedings \\
\hline & \\
245 & 54.4 \\
35 & 7.8 \\
86 & 19.1 \\
11 & 2.4 \\
27 & 6.0 \\
23 & 5.1 \\
8 & 1.8 \\
3 & 0.7 \\
12 & 2.7 \\
450 & 100.0 \\
\hline
\end{tabular}

High volume (e.g. set dates)

First appearance

Bail

Plea

Sentencing

5.1

Plea + Sentencing

1.8

Trial + Sentencing

2.7

Total

450 
$\underline{\text { Table 2. Actual and Ideal Parental Roles in Youth Justice Proceedings }}$

\begin{tabular}{cccc}
\hline No Role & Support/Guidance & Advocacy & Socialization
\end{tabular}

\begin{tabular}{lcccccccc}
\cline { 2 - 8 } Respondent Group & Actual & Ideal & Actual & Ideal & Actual & Ideal & Actual & Ideal \\
Police $(\mathrm{n}=10)$ & 6 & 0 & 6 & 6 & 1 & 3 & 1 & 8 \\
Defence $(\mathrm{n}=8)$ & 1 & 0 & 5 & 6 & 6 & 4 & 3 & 4 \\
Crown $(\mathrm{n}=7)$ & 1 & 1 & 5 & 6 & 4 & 4 & 4 & 4 \\
Judges $(\mathrm{n}=7)$ & 1 & 0 & 5 & 7 & 2 & 1 & 5 & 5 \\
Probation $(\mathrm{n}=9)$ & 2 & 1 & 5 & 8 & 6 & 3 & 4 & 7 \\
\hline Total $(\mathrm{n}=41)$ & 11 & 2 & 26 & 39 & 19 & 15 & 17 & 28 \\
\hline
\end{tabular}


Table 3. Parents' Attendance at Observed Court Proceedings by Type of Proceeding

\begin{tabular}{lllc}
\hline Type of Proceeding & $\begin{array}{l}\text { Number } \\
\text { proceedings } \\
\text { observed }\end{array}$ & $\begin{array}{l}\text { Number of proceedings } \\
\text { with parents present }\end{array}$ & $\begin{array}{l}\text { \% of proceedings } \\
\text { with parents present }\end{array}$ \\
\hline High Volume* & 280 & 173 & 61.8 \\
Bail & 86 & 80 & 93.0 \\
Plea & 11 & 6 & 54.5 \\
Trial & 27 & 18 & 66.7 \\
Sentencing** & 34 & 22 & 64.7 \\
Unclear/Missing & 12 & 7 & 58.3 \\
Total & 450 & 306 & \\
\hline
\end{tabular}

* Includes first appearances.

** Includes proceedings where the plea or trial took place during the same appearance as the sentencing. 
Table 4. Parents' Role at Observed Court Proceedings

\begin{tabular}{|c|c|c|c|}
\hline Parental Actions & $\mathrm{N}$ & $\begin{array}{l}\% \text { of Total Parent } \\
\text { Roles }(\mathrm{N}=509)\end{array}$ & $\begin{array}{l}\% \text { of Proceedings Where } \\
\text { Parents Present }(\mathrm{N}=306)^{*}\end{array}$ \\
\hline Addressed Court & 20 & 3.9 & 6.5 \\
\hline Addressed Judge & 26 & 5.1 & 8.5 \\
\hline Interacted with Youth & 45 & 8.9 & 14.7 \\
\hline Interacted with Defence Counsel & 72 & 14.1 & 23.5 \\
\hline Interacted with Crown Counsel & 30 & 5.9 & 9.8 \\
\hline Remained seated when case called & 157 & 30.9 & 51.3 \\
\hline Rose with youth when case called & 109 & 21.4 & 35.6 \\
\hline $\begin{array}{l}\text { Parent acted as witness/testified (either } \\
\text { during bail or other proceeding) }\end{array}$ & 50 & 9.8 & 16.3 \\
\hline Total & 509 & 100.0 & \\
\hline
\end{tabular}

* Note: Percentages in this column are based on 306 separately observed proceedings where parents were present, and add to more than $100 \%$ because in a number of proceedings attended by parents they assumed more than one role. 
Table 5. Youth Justice Perspective on Parents' Influence on Legal Proceedings

\begin{tabular}{lcccccc}
\hline Group & $\mathrm{N}^{*}$ & Support & $\begin{array}{c}\text { Legal } \\
\text { Advantage }\end{array}$ & $\begin{array}{c}\text { Socialization } \\
\text { Supervision }\end{array}$ & $\begin{array}{c}\text { Disadvantage } \\
\text { Conflict }\end{array}$ & Other \\
\hline Police & 10 & 0 & 9 & 0 & 0 & 1 \\
Defence & 8 & 2 & 8 & 0 & 3 & 0 \\
Crown & 7 & 1 & 7 & 1 & 1 & 0 \\
Judges & 7 & 0 & 7 & 1 & 2 & 0 \\
Probation & 9 & 1 & 9 & 0 & 0 & 0 \\
\hline Total & 41 & 4 & 40 & 2 & 6 & 1 \\
\hline
\end{tabular}

*Row N's do not total to the number of participants in each respondent group because coding categories were not mutually exclusive; participants may have expressed views that were coded into multiple categories. 


\section{$\underline{\text { Endnotes }}$}

${ }^{1}$ In this paper the term 'parent' is not restricted to biological parents, adoptive parents, or legal guardians but includes individuals (e.g., grandparents, siblings, or other relatives) who assume one or more parenting roles with respect to youth such as providing advice, guidance, support or assuming responsibility for the wellbeing of youth.

${ }^{2}$ Visible minority status was defined in terms of 'white vs. non-white'. Inter-observer reliability for this variable was good.

${ }^{3}$ For six participants it was unclear whether the defendant was represented by duty counsel or private lawyer and three cases were not observed to have legal representation.

${ }^{4}$ Individuals were coded as parents either as a result of being identified as such by someone in the courtroom (typically the youth's lawyer or duty counsel) or when it was clear to the observer that a person was a 'parent' (e.g., because youth and parents were observed together either in the courtroom or outside the courtroom before or after the proceedings. Inter-observer reliability for coding of parent's presence or absence was good.

${ }^{5}$ Interestingly, some aspects of this socialization function that police desire may be the same things that defence counsel are concerned about (e.g., parental actions that are contrary to the legal interests of youth).

${ }^{6}$ Judges $(n=3)$, crown counsel $(n=2)$, probation officers $(n=2)$ and police $(n=2)$ also spontaneously noted this issue.

${ }^{7}$ Parental attendance at plea appearances may be low due to the prior negotiation of plea agreements at pretrial meetings that rendered these appearances a 'done deal'.

${ }^{8}$ Note that on two or three occasions court officials requested that anyone not involved as a witness be removed from the courtroom. This procedure might have caused observers to miss 
interactions that parents with the court. Also note that some trial and sentencing hearings lasted several days. It was not possible to follow defendants throughout their case. Thus, some information on parents' involvement might have been missed.

${ }^{9}$ Youths' views about their parents' involvement is examined in several papers (Broeking and Peterson-Badali, 2009a, b; Peterson-Badali and Broeking, 2004).

${ }^{10}$ Interestingly, no association was found between type of charge (violent versus non-violent) and outcomes of bail hearings, $\chi^{2}(1, \mathrm{~N}=66)=.85, \mathrm{p}=.36$. It was not possible to examine the relationship between prior convictions and bail outcomes as no data on this variable could be collected during courtroom observations. 